\title{
Analysis
}

\section{Budget crises, health, and social welfare programmes}

BMJ 2010; 340 doi: http://dx.doi.org/10.1136/bmj.c3311 (Published 24 June 2010) Cite this as: BMJ 2010;340:c3311

- Article

- Related content

- Metrics

- Responses

- Peer review

- 6

David Stuckler, researcher 12, Sanjay Basu, physician3, Martin McKee, professor of European public health4

\section{Author affiliations}

Correspondence to: D Stuckler David.stuckler@chch.ox.ac.uk Accepted 27 May 2010

Governments may feel they are protecting health by safeguarding healthcare budgets, yet David Stuckler, Sanjay Basu, and Martin McKee argue that social welfare spending is as important, if not more so, for population health

The recession of 2008 has had profound economic consequences for many countries. How and when to reduce budget deficits was a major focus in the recent general election in the United Kingdom and continues to make headlines around the world. The new government has already begun to make large cuts in public expenditure,1 2 even though the UK's projected underlying debt, as a share of gross domestic product (GDP), is less than that of other industrialised countries, it has longer than many other countries before it is required to refinance loans (table $1 \underline{\Downarrow}$ ), and the actual deficit in 2009-10 was considerably less than expected. Leading economists have widely divergent views about whether the cuts will aid or hinder economic recovery, $\mathbf{3}$ but have paid scant attention to the potential effects of reductions in health and social expenditure on population health.5 We examine historical data for insights into how lower levels of public spending might affect health.

\begin{tabular}{|l|c|c|c|}
\hline Country & $\begin{array}{c}\text { Deficit as } \\
\% \text { of GDP }\end{array}$ & $\begin{array}{c}\text { Gross debt as } \\
\text { a \% of GDP }\end{array}$ & $\begin{array}{c}\text { Average maturity of } \\
\text { government debt (years) }\end{array}$ \\
\hline Germany & -5.7 & 72.5 & 6.0 \\
\hline US & -11.0 & 83.2 & 4.4 \\
\hline France & -8.2 & 77.4 & 6.5 \\
\hline
\end{tabular}




\begin{tabular}{|l||c||c||c|}
\hline UK & -11.4 & 68.2 & 12.8 \\
\hline Greece & -8.1 & 115.1 & 7.4 \\
\hline Japan & -9.8 & 217.7 & 5.2 \\
\hline Italy & -5.2 & 115.8 & 6.7 \\
\hline Portugal & -8.8 & 77.1 & 6.2 \\
\hline GDP=gross domestic product. & & \\
\hline
\end{tabular}

View this table:

- $\quad$ View popup

- $\underline{\text { Collapse inline }}$

\section{Wider view of health spending}

What little discussion there has been about health in the current economic recession has focused on whether to ringfence NHS spending. 6 This is a narrow perspective given the extensive evidence that population health is not only determined by healthcare expenditure but by many factors outside the health system. The evidence, most recently reviewed in detail by Michael Marmot in his report to the British government on health inequalities, 7 has highlighted how investments in a variety of social policies benefit health. Thus, children who receive better education, have safe environments in which to play, and who live in good quality housing are more likely to grow up healthy than those who do not. Adults in secure and safe employment, receiving wages above the level needed merely to survive, are less likely to adopt hazardous lifestyles (such as smoking, drinking, or unhealthy diets) and can expect to live longer.

Yet the implications of this evidence for the welfare state are contested. Do they imply the need for a well functioning welfare state that can support people at all stages of their lives, actively seeking to promote wellbeing for all? Or is the welfare state part of the problem, driving out individual initiative and creativity to produce a culture of dependency that stifles the emergence of an improved society? These divergent views have led to a political debate characterised by, on the one hand, calls for ever greater "efficiency savings," 8 which is increasingly seen as a euphemism for budget cuts, and, on the other, calls for "stronger social safety nets . . . to protect the most vulnerable in rich and poor countries" in the context of losses of income, increased unemployment, and overall economic insecurity. 9

\section{What do the data show?}

One way to inform this debate is to examine whether there is a historical association between levels of social spending and population health outcomes. We evaluated data on social welfare spending collected by the Organisation for Economic Cooperation and Development (OECD), 10 with age standardised all cause mortality in the 15 European Union countries for which comparative data are 
available over the past three decades (Austria, Belgium, Lenmark, rinland, rrance, Germany, Greece, Ireland, Italy, Luxembourg, Netherlands, Portugal, Spain, Sweden, and the United Kingdom).10 This covers 1980-2005, although mortality data for Belgium were available up to only 1998.11

The OECD defines social welfare expenditure as "the provision by public (and private) institutions of benefits to, and financial contributions targeted at, households and individuals in order to provide support during circumstances which adversely affect their welfare."10 This includes spending related to family support programmes (such as preschool education, child care, and maternity or paternity leave), old age pensions and survivors benefits, health care, housing (such as rent subsidies), unemployment benefits, active labour market programmes (to maintain employment or help the unemployed obtain jobs), and support for people with disabilities.712 13 All of these could plausibly affect health. Although the OECD has developed standardised definitions and harmonised data collection to ensure comparability across countries, we adjusted the data further to take account of purchasing power parity and inflation. Figure $1 \underline{\underline{\Downarrow}}$ shows a clear association between social welfare spending and mortality in 2000 across EU countries $(r=-0.78, \mathrm{P}<0.001)$.

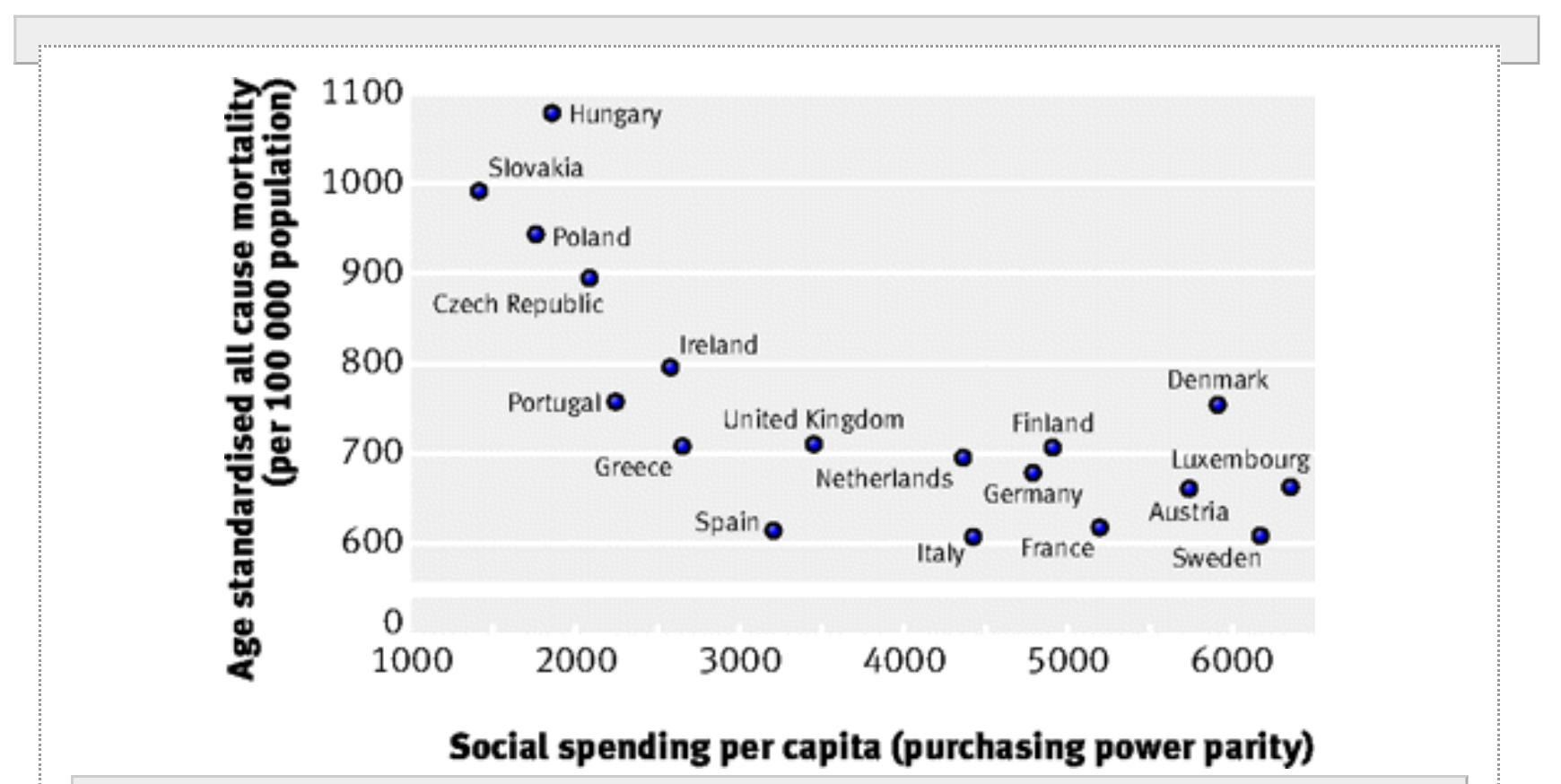

Fig 1 Relation between social welfare spending and all cause mortality in 18 EU countries, 2000

However, to quantify this relation, it is necessary to look at results over time and to take account of other factors that might explain this apparent association, such as remaining differences in categorising spending or underlying differences in mortality. We therefore corrected for fixed country differences (by including country dummy variables), reporting estimates of the long term relations between social spending and health within each country. Given that the timing of the effect of differences in social spending is uncertain, the method we used enabled us to account for any potential lagged effects (up to a decade) by estimating mean country specific slopes relating social spending to health.14 Figure $2 \underline{\Downarrow}$, in which each point represents each country in each year, shows a clear association between social welfare spending and all cause mortality after adjustment for any country specific factors. If no country 
aeviatea trom tne average socıaı weırare spenaıng, alı points wouıd cıuster at zero.

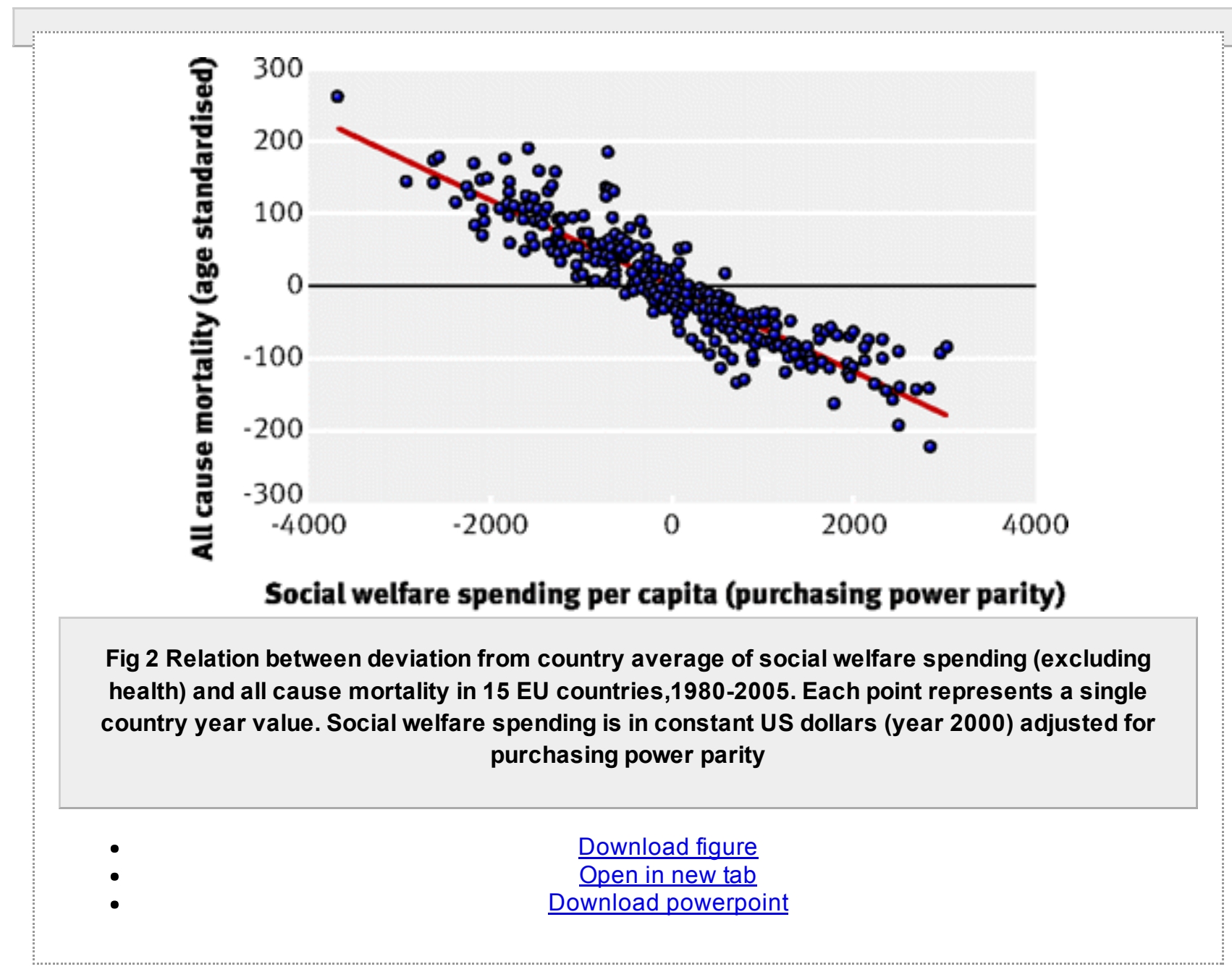

The models constructed show that each additional $\$ 100$ increase in social welfare spending has been associated with a $1.19 \%$ drop in all cause mortality (table $2 \underline{\Downarrow}$ ). Crucially, our findings were specific to social welfare spending (as defined above); there was no observable protective effect associated with general government spending, which is understandable since military, prison, or similar spending would not be expected to have a visible public health effect.

\section{Table 2}

Effect of $\$ 100$ of income, social welfare, and general government spending on all cause mortality for 15 EU countries, 1980-2005 (purchasing power parity in $\$$ for 2000)

View this table:

- View popup

- View inline
Clearly, it is important to take account of the probability that richer countries will spend more, which could produce an artefactual association between good health (as a result of relative wealth) and overall higher social welfare spending. As in previous research, we found that higher GDP was indeed associated with lower mortality (each $\$ 100$ increase in

GDP was significantly associated with a $0.11 \%$ fall in all cause mortality).15 16 However, we also found that a comparable rise in social welfare spending was associated with over a sevenfold greater reduction in mortality of than a similar magnitude rise in GDP $(0.80 \% v 0.11 \%$, table 2[t2]. Furthermore, when we adjusted for social welfare spending, the association of GDP with lower mortality was cut by 
increased wealth crucially depend not just on increasing income but on what fraction goes into social welfare spending from governments.

\section{Comparing social spending with healthcare spending}

We recognise that correlation may not mean causation; we also need to consider multicolinearity (multiple variables that happen to change together) and the potential for undetected confounding that constrains our ability to isolate the effects of social welfare spending on public health. One way to screen for this problem is by comparing mortality from causes where there would not plausibly be a short term relation between health and social spending, such as most cancers, with mortality from diseases where we would expect to see changes with spending, such as alcohol related deaths. Our findings are in line with predictions (table $3 \underline{\Downarrow}$ ) supporting the idea that our findings are not simply due to multicolinearity.

\begin{tabular}{|c|c|c|c|c|}
\hline Covariate & All cause & $\begin{array}{l}\text { Alcohol } \\
\text { related }\end{array}$ & $\begin{array}{c}\text { Malignant } \\
\text { neoplasms }\end{array}$ & $\begin{array}{c}\text { Cardiovascular } \\
\text { disease }\end{array}$ \\
\hline $\begin{array}{l}\$ 100 \text { in } \\
\text { income } \\
\text { per capita }\end{array}$ & $\begin{array}{l}-0.14 \% * * \\
(0.035)\end{array}$ & $\begin{array}{c}-0.21 \% \\
(0.12)\end{array}$ & $\begin{array}{l}-0.034 \% \\
(0.034)\end{array}$ & $\begin{array}{c}-0.31 \%{ }^{* *} \\
(0.084)\end{array}$ \\
\hline $\begin{array}{l}\$ 100 \text { rise } \\
\text { in social } \\
\text { welfare } \\
\text { spending } \\
\text { (excluding } \\
\text { health } \\
\text { care) }\end{array}$ & $\begin{array}{c}-0.99 \% * * * \\
(0.11)\end{array}$ & $\begin{array}{c}-2.80 \% * * * \\
(0.46)\end{array}$ & $\begin{array}{l}-0.065 \% \\
(0.18)\end{array}$ & $-1.23 \% * *(0.31)$ \\
\hline $\begin{array}{l}\$ 100 \text { rise } \\
\text { in } \\
\text { healthcare } \\
\text { spending }\end{array}$ & $\begin{array}{l}-0.01 \% \\
(0.43)\end{array}$ & $\begin{array}{l}0.97 \% \\
(0.90)\end{array}$ & $\begin{array}{c}-0.82 \% \\
(0.47)\end{array}$ & $-0.28 \%(0.95)$ \\
\hline $\begin{array}{l}\text { No of } \\
\text { country- } \\
\text { years }\end{array}$ & 320 & 319 & 319 & 319 \\
\hline $\mathrm{R}^{2}$ & 0.906 & 0.773 & 0.535 & 0.901 \\
\hline \multicolumn{5}{|c|}{$\begin{array}{l}\text { Countries were Austria, Belgium, Denmark, Finland, France, Germany, Greece, } \\
\text { Ireland, Italy, Luxembourg, Netherlands, Portugal, Spain, Sweden, and United } \\
\text { Kingdom. Robust standard errors in parentheses clustered by countries to } \\
\text { reflect non-independence of sampling. }\end{array}$} \\
\hline \multicolumn{5}{|c|}{ 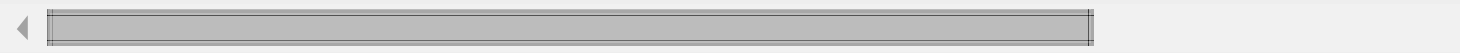 } \\
\hline
\end{tabular}


View this table:

- $\quad$ View popup

- $\underline{\text { Collapse inline }}$ politicians have promised to protect the NHS at the expense of other services, a key question is whether the association between social welfare spending and mortality is driven by expenditures on health care or by the social spending programmes. Table $3 \Uparrow$ shows that social spending was significantly associated with mortality from

diseases related to social circumstances (such as alcohol related deaths) but healthcare spending was not. Thus although increases in social welfare spending overall are associated with reduced mortality from these conditions, the effect is due to spending on areas other than health. Future research should look at the effect of different types of social spending (employment versus housing for example). For now, this result indicates that some aspects of population health are more sensitive, in the short term, to spending on social support than on health care, although a caveat is necessary as these countries have not experienced changes in healthcare funding of the scale that might be expected to affect health. Nevertheless, the maintenance of social welfare programmes seems to be a key determinant of future population health that should be taken into account in ongoing economic debates.

\section{Implications for public health practice}

The delivery of public services in the UK is recognised to be impeded by pervasive silo mentalities, with interagency collaboration hampered by poor communication and different styles of operation.17 Previous attempts to overcome these problems, such as the creation of health action zones, have had little success.18 In some cases, the consequences of this failure are highly visible, such as the high profile deaths of young children at the hands of their carers where problems were missed because of poor communication between several agencies. More often, however, the problems go unnoticed, except by those people who struggle as they go from agency to agency, seeking an integrated assistance package for complex needs. There is a real danger that spending cuts could accentuate this problem, encouraging each organisation to behave opportunistically, transferring as much responsibility for complex problems to others, and concentrating only on the narrow targets they can use most easily to justify their existence.19

Yet there are also some positive avenues for action. One example attracting considerable attention is the Total Place programme, now involving 13 communities across England.20 This seeks to develop new ways that different agencies can work together. It has three elements: counting (tracking financial flows to agencies and identifying ways in which money can be spent most effectively), culture (determining whether organisational cultures help or hinder service delivery, and how to facilitate their improvement), and customer needs (placing the central focus on service users). The agencies involved in each scheme vary, but many include local government, primary care trusts, police and fire authorities, employment and welfare agencies, and regional development organisations. Some have also included the non-governmental sector. The pilots are currently being evaluated by researchers from the University of Birmingham, but they have already provided many examples of how government agencies can work across institutional boundaries.20 There are also many smaller local initiatives that work across sectors, exemplified by the diverse range of high quality submissions for the chief medical officer's public health awards.21

Sir Michael Marmot's recent review on health inequalities in the United Kingdom concluded that "Austerity need not lead to retrenchment in the welfare state. Indeed, the opposite may be necessary."7 The current economic difficulties could be viewed as an opportunity to reorganise provision of services to those in need, creating a broader set of services that reflect the increasingly complex needs of a 
society facing health challenges as varied as fast food and dementia. It would be unfortunate if this opportunity were wasted. If the first priority of a government is to protect the lives of its people, a statement often made in response to the perceived threat from terrorism, 22 then it should take account of the implications of its economic policies for health.

\section{Notes}

Cite this as: BMJ 2010;340:c3311

\section{Footnotes}

- Contributors and sources: DS, SB, and MMcK have published extensively on the determinants of health in societies undergoing social and economic transition. The idea came out of discussions among DS, SB, and MMcK. DS did the analyses and drafted the paper, which SB and MMcK revised.

- Competing interests: All authors have completed the unified competing interest form at www.icmje.org/coi_disclosure.pdf (available on request from the corresponding author) and declare (1) no financial support for the submitted work from anyone other than their employer; (2) no financial relationships with commercial entities that might have an interest in the submitted work; (3) no spouses, partners, or children with relationships with commercial entities that might have an interest in the submitted work; and (4) no non-financial interests that may be relevant to the submitted work.

- Provenance and peer review: Not commissioned; externally peer reviewed.

\section{References}

1. $\downarrow$ International Monetary Fund. Fiscal monitor. IMF, 2010.

2. $\lrcorner$ Stuckler D, Basu, S, McKee, M, Suhrcke, M. Responding to the economic crisis: a primer for public health professionals. J Pub Health (forthcoming).

3. $\downarrow$ Eaglesham J, Pimlott, D. Economists reject calls for budget cuts. Financial Times2010 February 18.

4. $\downarrow$ Giles C, Pimlott, D, Eaglesham, J. UK deficit warning from City economists. Financial Times2010 January 3.

5. $\downarrow$ Stuckler D, Basu, S, McKee, M. How government spending cuts put lives at risk. Nature2010;465:289. Medline $\underline{\text { Web of Science }}$

6. $\downarrow$ Appleby J, Crawford, R, Emmerson, C. How cold will it be? Prospects for NHS funding: 2011-2017. London: King's Fund, 2009.

7. $\downarrow$ Marmot M. Fair society, healthy lives. University College London, 2010.

8. $\lrcorner$ Porter A. Business leaders hit back at 'patronising' Labour claims on Tory NI plan. Daily Telegraph2010 Apr 1. www.telegraph.co.uk/news/election-2010/7543905/Business-leaders-hit-back-at-patronising-Labour-claimson-Tory-Nl-plan.html.

9. $\downarrow$ WHO. Financial crisis and global health: report of a high-level consultation. WHO, 2009.

10. $\downarrow$ OECD. Organisation for Economic Co-operation and Development social expenditure data. OECD, 2008. 
11. $\downarrow$ WHO. WHO European health for all database. 2008. http://data.euro.who.int/hfadb/.

12. $\downarrow$ Stuckler D, Basu S, Suhrcke M, Coutts A, McKee M. The public health impact of economic crises and alternative policy responses in Europe. Lancet2009;374:315-23. CrossRef Medline Web of Science

13. $\downarrow$ Marmot M, Friel S, Bell R, Howeling AJ, Taylor S. Closing the gap in a generation: health equity through action on the social determinants of health. Lancet2008;372:1661-9. CrossRef Medline Web of Science

14. $\downarrow$ Jones A. Health econometrics. In: Cuyler A, Newhouse, JP, ed. Handbook of health economics. Elsevier Science, 2000:265-344.

15. $\downarrow$ Swift R. The relationship between health and GDP in OECD countries in the very long run. Health Econ (forthcoming).

16. $\downarrow$ Pritchett L, Summers LH. Wealthier is healthier. J Hum Resources 1996;31:841-68. CrossRef Web of Science

17. $\lrcorner$ Sloper P. Facilitators and barriers for co-ordinated multi-agency services. Child Care, Health Develop 2004;30:571-80. $\underline{\text { CrossRef }}$

18. $\downarrow$ Berkeley D, Springett J. From rhetoric to reality: barriers faced by Health for All initiatives. Soc Sci Med2006;63:179-88. CrossRef Medline Web of Science

19. $\downarrow$ Wismar M, McKee M, Busse R, Ernst K. Targets for health: uses and abuses. European Observatory on Health Systems and Policies, 2008.

20. $\downarrow$ Total Place. Total Place: better for less. 2010. www.localleadership.gov.uk/totalplace.

21. DDepartment of Health. Chief medical officer's public health awards 2010. www.cmoawards.org.uk.

22. $\sqcup$ McKee M, Coker R. Trust, terrorism, and public health. J Public Health2009;31:462-5. Abstract/FREE Full Text

Y Tweet

- f Like 0

- $\mathbf{G}+1\} 0$

\title{
Article tools
}

7 responses

- $\mathscr{R}$ Respond to this article

- BPrint

- AAlerts \& updates

\section{Article alerts}

Please note: your email address is provided to the journal, which may use this information for marketing purposes.

\section{Log in or register:}

\author{
Username * \\ Password *
}

\section{Log in}

